\title{
JURNAL ARTIKULA
}

ISSN (print) 2615-191X || ISSN (Online) 2615-1901

\section{Penggunaan Bahasa pada Masyarakat Bermatapencaharian Pedagang di Pangandaran dalam Aktivitas Perdagangan}

\author{
Nanang Maulana ${ }^{1}$ \\ ${ }^{1}$ Universitas Mathla'ul Anwar Banten
}

\begin{tabular}{l} 
ARTICLE INFO \\
\hline Article History: \\
Received 10.07.2018 \\
Received in revised \\
form 14.08.2018 \\
Accepted 19.09.2018 \\
Available online \\
27.09.2018
\end{tabular}

\begin{abstract}
Languages such as land that has no end to cultivate or become the object of research by researchers, the nature of dynamic language allows researchers to find new cases or even current theories. In addition, the breadth of language studies makes language can be studied or examined from various perspectives, both from the internal or external language itself.In a study entitled "The Use of Language in Livelihoods Traders in Pangandaran in Trading Activities" this language was studied from a sociolinguistic perspective and aimed to find out or know the language usage of traders in Pangandaran in trading activities. Based on the results of the research conducted shows that a) the language usage of traders in Pangandaran tends to use their respective regional languages as proof of language revitalization or retention b) Many phonemes are used when the traders carry out their trading activities c) There is language interference d) Available code switching or mixed code among traders in Pangandaran e) Language influenced by the speakers' background, especially in this research is culture. This type of research is a qualitative descriptive research while data collection techniques in this study are literature review, observation, data collection and analysis.

Keywords: Language, Pangandaran, Trader Community.
\end{abstract}

This is an open access article distributed under the terms of the Creative Commons Attribution 4.0 International License, which permits unrestricted use, distribution, and reproduction in any medium, provided the original work is properly cited. (c) 2018 Nanang Maulana.

\section{PENDAHULUAN}

Bahasa merupakan alat komunikasi manusia yang sangat penting. Melalui bahasa menusia dapat berinteraksi dan bersosialisasi dengan lingkungannya. Berdasarkan pernyataan di atas akhirnya manusia berupaya untuk mempelajari bahasa. Untuk memenuhi tuntutan tersebut, bahasa diajarkan dalam setiap jenjang pendidikan.

Manusia menggunakan bahasa sebagai alat komunikasi. Kehadirannya memiliki tugas untuk memenuhi salah satu kebutuhan sosial manusia, menghubungkan manusia 
satu dengan manusia yang lain di dalam peristiwa sosial tertentu. Peran penting bahasa dalam kehidupan manusia disadari sebagai kebutuhan primer dalam kehidupan sosial.

Bahasa dapat dikaji dari sudut pandang keilmuan. Ilmu yang menjadikan bahasa sebagai objek kajiannya disebut Linguistik. Awalnya linguistik adalah sebuah disiplin ilmu yang mandiri, namun dalam perkembangannya, linguistik dapat pula melibatkan beberapa disiplin ilmu pengetahuan yang lain. Ini berarti linguistik menjadi bersifat multidisipliner.

Dalam kaitan tersebut dikenal beberapa studi bahasa yang melibatkan disiplin ilmu lain. Misalnya psikolinguistik yang mempelajari proses mental dalam hubungannya dengan cara-cara perolehan bahasa dan pilihan bahasa. Selanjutnya adalah sisiolinguistik yang menyoroti keseluruhan masalah yang berhubungan dengan organisasi social prilaku bahasa, tidak hanya mencakup pemakaian bahasa saja, melainkan juga sikapsikap bahasa, perilaku terhadap bahasa dan pemakaina bahasa (Sumarsono, 2009; 1).

Manusia adalah mahkluk sosial. Artinya, manusia memiliki kebutuhan untuk bersosialisasi. Oleh karena itu manusia membutuhkan kehadiran manusia lain untuk memenuhi kebutuhan sosialnya. Hal ini kemudian memunculkan kelompok-kelompok manusia dengan kesamaan tertentu yang disebut sebagai masyarakat. sehingga terciptalah sebuah interaksi social di masyarakat yang dilakukan dengan menggunakan bahasa.

Dalam interaksi di masyarakat inilah timbul beberapa perilaku berdasarkan pemikiran masing-masing sehingga lahirlah kebiasaan atau budaya. Budaya dan kebiasaan ini akan berbeda tergantung siapa dan di mana bahasa atau pengguna bahasa itu berada. Faktor lain yang ikut andil dalam pembeda adalah perbedaan geografis, latar belakang sejarah, disebabkan juga oleh perbedaan sosial seperti status sosial, tingkat pendidikan, umur, jenis kelamin, budaya dan lain-lain.

Setiap orang dari budaya yang berbeda maka secara otomatis penggunaan bahasanya pun akan berbeda, bahasa yang digunakan seseorang akan mencerminkan budayanya sendiri. Karena seperti apa yang dikatakan di atas bahwa bahasa merupakan produk sosial atau produk budaya. Misalnya, penggunaan bahasa orang terminal akan berbeda dengan penggunaan bahasa orang pesantren, begitu juga penggunaan bahasa pedagang akan berbeda dengan penggunaan bahasa seorang sastrawan.Perbedaan penggunaan bahasa disetiap kalangan mempunyai keunikan dan ciri sendiri, dan menggoda berbagai ilmuwan atau para akademisi untuk melakukan sebuah penelitian sehingga didapat karakteristik penggunaan bahasa dari setiap orang yang mempunyai profesi berbeda sebagai hasil dari kebudayaan

Menurut Koentjaraningrat dalam Abdul Chaer (2004:165) mengatakan bahwa bahasa bagian dari budaya. Jadi hubungan antara bahasa dan budaya merupakan hubungan yang subordinatif, dimana bahasa berada di bawah lingkup kebudayaan. Tetapi, ini bukanlah salah satunya konsep yang ada dibicarakan orang, sebab di samping itu ada pendapat lain yang menyatakan bahwa bahasa dan kebudayaan mempunyai hubungan koordinatif, yakni hubungan yang sederajat, yang kedudukannya sama tinggi. Malah Masinambouw (1985) masih dalam Chaer (2004:165) mengatakan bahwa bahasa dan budaya merupakan dua sistem yangmelekat pada manusia. Kalau budaya itu adalah satu sistem yang mengatur manusia di dalam masyarakat, maka kebahasaan adalah sistem yang berfungsi sebagai sarana berlangsungnya interaksi itu.

Menurut Chaer (2004:166) mengenai hubungan bahasa dan kebudayaan yang bersifat koordinatif ada dua hal yang perlu diperhatikan yaitu pertama ada yang 
mengatakan hubungan kebahasaan dan kebudayaan itu seperti anak kembar siam, dua buah fenomena yang terikat erat, seperti hubungan antar sisi yang satu dengan sisi yang lainnya, jadi pendapat ini mengatakan bahwa kebahasaan dan kebudayaan merupakan dua fenomena yang berbeda tetapi mempunyai hubungan yang sangat erat, sehingga tidak dapat dipisahkan. Kedua dalam hubungan koordinatif ini adalah adanya hipotesis yang sangat kontroversial, yaitu hipotesis dari dua fakat linguis ternama yaitu Edward Sapir dan Benjamin Lee Whorf. Karena itu, hipotesis ini dikenal dengan hipotesis SapirWhorf dan lazim disebut relativitas bahasa.

Hipotesis Whorf (Whorfian Hypothesis) dalam buku An Introduction to Sosiolinguistic(2006) karangan Ronal Wardhaugh mengatakanstruktur bahasa sangat mempengaruhi bagaimana pembicara memandang dunia serta hubungannya dengan dunia luar (eksternal). Oleh karena itu jenis kosakata, susunan kosakata/kalimat, dan tata bahasa sangat mempengaruhi perilaku seseorang.

\section{METODE}

Syamsuddin dan Vismaia (2006:14) mengatakan, metode penelitian merupakan cara pemecahan masalah penelitian yang dilaksanakan secara terencana dan cermat dengan maksud mendapatkan fakta dan simpulan agar dapat memahami, menjelaskan, meramalkan dan mengendalikan keadaan. Metode penelitian juga merupakan cara kerja untuk memahami dan mendalami objek yang menjadi sasaran dalam penelitian.

Dalam penelitian ini penulis menggunakan metode deskriptif analitik. Metode ini dilakukan dengan cara mengumpulkan data, menyusun atau mengklasifikasikan data, menganalisis kemudian berusaha mendeskripsikan data kebahasaan dalam bentuk kalimat bahasa Indonesia yang sifatnya tertulis.

Agar data dapat terkumpul dengan baik, penulis menggunakan teknik-teknik pengumpulan data dengan tahap-tahap: 1) Telaah Pustaka; 2) Observasi; 3) Pengumpulan data; dan 4) Analisis.

\section{PEMBAHASAN}

Salah satu yang menjadi pertemuan orang-orang dari berbagai latar belakang yang berbeda adalah objek wisata. Di sini, kontak bahasa antar manusia yang berbeda latar belakang terjadi dan memungkinkan adanya alih kode atau campur kode.

Pangandaran adalah sebuah tempat objek wisata yang terletak di Kabupaten Pangandaran Provinsi Jawa Barat. Pada awalnya, Pangandaran merupakan bagian dari Kabupaten Ciamis, namun, dimekarkan secara otonom sehingga menjadi Kabupaten Pangandaran. Pemekaran tersebut salah satunya didasarkan pada luasnya wilayah Pangandaran dan banyaknya penduduk Pangandaran. Selain penduduk asli, banyak juga para pendatang yang menetap di sana dengan tujuan untuk berjualan, atau hanya sekedar wisata sehingga dari banyaknya penduduk dan orang dari luar Pangandaran yang masuk, secara tidak disadari maka kebudayaan dan bahasa pun menjadi sangat beragam.

Dalam aktivitas perdagangannya masyarakat pedagang pangandaran umumnya menggunakan bahasa Sunda, Jawa dan Indonesia tergantung latar belakang budaya dan asal pedagang itu sendiri. Tidak menutup kemungkinan ke tiga bahasa tersebut ikut mempengaruhi pedagang yang berlatarkan sunda. Begitu pun pedagang yang berlatarkan jawa. Artinya ke tiga bahasa di atas dalam penggunaannya saling memberikan pengaruh kepada penuturnya. Kecenderungan masyarakat yang 
menggunakan bahasa jawa, menggunakan bahasa yang bercampur dengan bahasa sunda, sebab mayoritas sudah lama menetap di Pangandaran sehingga mereka bisa menggunakan bahasa sunda walau pun hanya sebagaian saja. Adapun penduduk asli Pangandaran mayoritas menggunakan bahasa sunda atau bahasa Indonesia yang bercampur dengan unsur-unsur bahasa sunda seperti mah, atuh, da serta bahasa sunda lainnya.

Di lapangan ditemukan bahwa penggunaan bahasa para pedagang di Pangandaran menggunakan bahasa daerah atau bahasa ibu si pedagang. Misalnya orang Jawa menawarkan barang dengan kata monggo pada kalimat "monggo A silahkan bajunya". Begitu juga pedagang dengan latar belakang sunda menggunakan "hayu" pada kalimat tawaran "hayu lah A naek parahu ningali terumbu karang". Tetapi tidak sedikit juga yang menggunakan bahasa Indonesia seperti kata silahkanpada kalimat "sepuluh ribu saja $A$ perjamnya, silahkan A dipilih saja sepedahnya murah A segitumah". Yang lebih menarik lagi ada beberapa yang dalam aktivitas perdagangannya menggunakan bahasa campuran, misalnya pada kalimat "kadarieu kadarieusilahkan dipilih-dipilih bajunya, baju barongnya, limapuluan limapuluan". Dari hasil temuan tersebut dapat diambil benang merah bahwa penggunaan bahasa oleh para pedagang Pangandaran dalam aktivitas perdagangannya masing-masing menggunakan bahasa daerahnya sendiri. Selain itu, ada juga pedagang yang memilih mencampuradukan bahasa daerah dengan bahasa Indonesia.

Temuan lain yang penulis temukan yaitu dalalm memulai aktivitas perdagangannya, para pedagang selalu memulainya dengan menggunakan bahasa Indonesia, hal tersebut dilakukan agar maksud atau pesan si pedagang dapat diterima oleh calon pembeli. Setelah terjadi kontak bahasa biasanya para pedagang mengeluarkan istilah perdagangan dari daerahnya masing-masing. Mereka menawarkan barang dagangannya dengan penuh perhatian dan senyuman dengan tujuan agar menarik minat calon pembeli.

Seperti yang telah penulis singgung di atas bahwa setiap pedagang dalam aktivitas perdagangannya mempunyai cara tersendiri. Ada yang menawarkannya dengan kata monggo, mangga, sok, hayu dan ngalarisan sesuai dengan bahasa daerahnya masing-masing. Penggunaan bahasa daerah dalam kalangan masyarakat yang multilingual seperti di Pangandaran ada kaitannya juga dengan revitalisasi bahasa atau pemertahanan bahasa, seta berhubungan juga dengan sopan santun berbahasa. Selain itu, penggunaan bahasa daerah terkesan luwes dan merasa berada di daerah sendiri khususnya bagi orang yang berasal dari luar Jawa Barat.

Kata tawaran, ajakan seperti di atasterkadang diucapkan dengan digabungkan dengan fonem dari bahasa lain, misalnya fonem mangga yang merupakan bahasa sunda digabungkan dengan fonem dari bahasa lain, sama halnya dengan partikel mah, atuh dan dayang penggunaanya digabungkan dengan bahasa Indonesia. Dalam sosiolinguistik fenomena tersebut dinamakan interferensi.

Bukan hanya interferensi, alih kode dan campur kode pun banyak terjadi di Pangandaran antara para pedagang dengan pembeli ketika sedang melakukan transaksi jual beli, apalagi antara penjual dan pembeli berbeda bahasa, suku, latar belakang pendidikan, usia dan lain sebagainya misalnya pada percakapan di bawah ini.

Penjual : silahkan A diliat-liat duhu kaosnya!

Pembeli : berapaan ini Teh?

Penjual : 70 ribu, bisa kurang kok A.

Pembeli : wah geuning mahal 
Penjual : sae irumah A barangna, tiis moal panas pami dianggo teh. Si Aa nawisna sabaraha atuh?

Pembeli : manawi teh tiasa 40 rebuan.

Penjual : wah teu acan kenging atuh A, ka abina ge teu ayaan 40 mah.

Pada percakapan di atas terjadi fenomena alih kode dari bahasa Indonesia ke bahasa sunda. Yaitu dimulai dari kata "berapaan ini Teh?" kemudian penjual menawarkan harga pertama yaitu 70 ribu, setelah itu pembeli kaget dan langsung beralih kode "wah geuninga mahal". Dari sana mulailah peralihan kode yang dikiuti juga oleh si penjual.

Pada penelitian yang dilakukan penulis rata-rata peralihan kode itu dimulai dari pembeli, setelah pembeli beralih kode pada bahasa sunda dari bahasa Indonesia, secara sepontan penjual pun akan ikut serta beralih kode, dengan catatan bahwa hal ini berlaku hanya untuk pembeli dan pedagang yang mempunyai kesamaan bahasa. Sedangkan untuk yang berbeda bahasa akan tetap menggunakan bahasa Indonesia dan tidak akan beralih kode, hal ini dimaksudkan agar komunikasi tetap berjalan lancar.

Untuk lebih jelasnya, penulis menyajikan tabel penggunaan bahasa pedagang di Pangandaran dalam aktivitas perdagangannya sebagai berikut.

Tabel 1. Data Responden

\begin{tabular}{llll}
\hline Nama Pedagang & Suku & Umur & Bahasa yang digunakan \\
\hline Inisial S & Jawa & 30 & Bahasa Jawa/Indonesia \\
\hline Inisial M & Sunda & 33 & Bahasa Sunda \\
\hline Inisial R & Sunda & 24 & Bahasa Sunda \\
\hline Inisial D & Sunda & 48 & Bahasa Sunda \\
\hline
\end{tabular}

Tabel 2. Fonem yang digunakan pada saat melakukan aktivitas perdagangan

\begin{tabular}{lll}
\hline Nama Pedagang & Suku & Fonem/frasa/kalimat \\
\hline Inisial S & Jawa & 1. Monggo \\
& & 2. Silahkan \\
& 3. Dipilih \\
& 4. Barang baru \\
& 5. Stok \\
& 6. Nego \\
& 7. Net \\
& 8. Pemasok \\
& 9. Toko \\
& 10. Link \\
& 11. Perang Tarif \\
\hline Inisial M & 1. Hayu \\
& 2. Mangga \\
& 3. Diliat-liat dulu \\
& & 4. Bisa kurang \\
& 5. Mahal \\
& 6. Nawis (nawar) \\
& 7. Ngalarisan \\
& & 8. Barang \\
\hline Inisial R & 1. Sok a sapedahna \\
& 2. Silahkan dipilih \\
& 3. Murah \\
& & 4. Rugi \\
\hline Inisial D & 1. Hayu \\
\hline
\end{tabular}




\begin{tabular}{|c|c|c|}
\hline & & $\begin{array}{l}\text { 2. Ngalarisan } \\
\text { 3. Mirah } \\
\text { 4. Nawar }\end{array}$ \\
\hline \multicolumn{3}{|c|}{ Tabel 3. Alih kode dan campur kode yang dilakukan respoden } \\
\hline Nama Pedagang & Suku & Alih kode/campur kode \\
\hline Inisial S & Jawa & $\begin{array}{l}\text { "Monggo , silahkan bajunya, dipake ja A } \\
\text { sandalnya, gak apa apa" } \\
\text { "Nyari opo mas? baju? Monggo dipilih dulu } \\
\text { barangkali ada yang cocok" } \\
\text { "Yo monggo mas sama sama" }\end{array}$ \\
\hline Inisial $\mathrm{M}$ & Sunda & $\begin{array}{l}\text { "Silahkan A diliat-liat dulu kaosnya!" } \\
\text { "70 ribu, bisa kurang kok A." } \\
\text { "Sae ieumah A barangna, tiis moal panas pami } \\
\text { dianggo teh. } \\
\text { "Si Aa nawisna sabaraha atuh?" }\end{array}$ \\
\hline Inisial R & Sunda & $\begin{array}{l}\text { "Sok A sapedahnya" } \\
\text { "Empat puluh ribu a perjamnya, jadi kalau } \\
\text { empat orang sepuluhribuan. Silahkan dipilih } \\
\text { aja sepedahnya murah da a segitumah" } \\
\text { "Wah rugi atut, hee.. ulah duapuluh atuh a" }\end{array}$ \\
\hline Inisial D & Sunda & $\begin{array}{l}\text { "Hayulah a naik parahu liat terumbu karang" } \\
\text { "ha, gak atuh A tenang ajah, moal nanaon da, } \\
\text { gakan apa-apa" } \\
\text { "mirah da A,, sok a bade nawar sabarah" }\end{array}$ \\
\hline
\end{tabular}

\section{SIMPULAN}

Berdasarkan hasil analisis penggunaan bahasa masyarakat bermatapencaharian pedagang di Pangandaran, penulis menyimpulkan beberapa hal yaitu sebagai berikut: 1 ) Bahwa penggunaan bahasa pedagang di Pangandaran cenderung menggunakan bahasa daerahnya masing-masing sebagai bukti repitalisasi atau pemertahanan Bahasa; 2) Banyak fonem-fonem yang digunakan ketika para pedagang tersebut melakukan aktivitas perdagangannya; 3) Adanya interferensi Bahasa; 4) Terdapat alih kode atau campur kode di antara pedagang di Pangandaran; dan 5) Bahasa dipengaruhi oleh latar belakang penuturnya khususnya dalam penelitian ini adalah budaya.

\section{REFERENSI}

Chaer, A. (2003). Linguistik umum. Jakarta: Rineka Cipta.

Chaer, A. (2004). Sosiolinguistik; Perkenalan awal. Jakarta: Rineka Cipta.

Hudson. (2001) Sosiolinguistic. New Jersey: Blackwell Publishing.

\section{KBBI Offline Versi V}

Ohoiwutun, P. (2002). Sosiolinguistik: Memahami bahasa dalam konteks masyarakat dan budaya. Bekasi: Percetakan KBI.

Sarosa, S. (2012). Penelitian kualitatif: Dasar-dasar. Jakarta: Indeks.

Sumarsono. (2009). Sosiolinguistik. Yogyakarta: Sabda. 
Syamsuddin, A. R., \& Damianti, V. S. (2006). Metode penelitian pendidikan bahasa. Bandung: Remaja Rosda Karya.

Wardhaugh, R. (2006). An introduction to sosiolinguistic. New Jersey: Blackwell Publishing. 